\title{
Identification of Intracellular Polysaccharide Granules in Thin Sections of Nocardia asteroides
}

\author{
By J. R. DIPERSIO* AND S. J. DEAL \\ Department of Microbiology, School of Medicine, West Virginia University, \\ Morgantown, West Virginia 26506, U.S.A.
}

(Received 3I January 1974; revised 8 April 1974)

\begin{abstract}
SUMMARY
Nocardia asteroides wVU strain 3672 accumulates storage polysaccharides when grown in a glucose-supplemented medium containing a growth-limiting concentration of nitrogen. Structural analysis of an isolated and purified sample identified the material as a glycogen-like polysaccharide possessing an average chain length of $1 \mathrm{I} \cdot 6$ glucosyl units and iodine absorption maximum at $460 \mathrm{~nm}$. Cytochemical staining of thin sections of whole organisms revealed granules ranging in size from 60 to $100 \mathrm{~nm}$ in diameter distributed throughout the cytoplasm. Glycogen granules could easily be differentiated from lipid storage vacuoles after treatment of thin sections with a glycogen-specific staining procedure. Negatively stained preparations of glycogen granules isolated with cold water revealed $\alpha$-particles composed of indistinct sub-units.
\end{abstract}

\section{INTRODUCTION}

A number of bacterial species synthesize glycogen-like polysaccharides under various environmental growth conditions. Although these compounds have been analysed chemically, ultrastructural methods have only occasionally been used to investigate glycogen storage in bacteria. A large number of cytoplasmic 'holes' ranging from 50 to $100 \mathrm{~nm}$ in diameter was found in thin sections of Escherichia coli grown under conditions favouring glycogen synthesis (Cedergren \& Holme, 1959; Holme \& Cedergren, I96I). No cytoplasmic 'holes' were seen in bacteria grown under conditions which restricted glycogen synthesis. Similar results were obtained with a strain of Streptococcus mitis which synthesized large amounts of glycogen (Berman, Gibbons \& Nalbandian, 1967). Cytoplasmic granules, approximately $60 \mathrm{~nm}$ in diameter, were observed. No such granules were formed in a mutant strain of this organism which was unable to synthesize glycogen. Glycogen granules have also been reported in thin sections of Myxococcus xanthus (Voelz, Voelz \& Ortigoza, 1966), Arthrobacter crystallopoietes (Boylen \& Pate, 1973) and certain ammonia- and nitrateoxidizing marine bacteria (Watson, Graham, Remsen \& Valoise, I97I; Watson \& Waterbury, 197I).

The purpose of the present work was to investigate the structure of storage polysaccharide isolated from Nocardia asteroides and to study the ultrastructural aspects of its accumulation.

* Present address : Department of Microbiology and Immunology, Temple University School of Medicine, Philadelphia, Pennsylvania, I9I40, U.S.A. 


\section{METHODS}

Bacterium. Nocardia asteroides wVU strain 3672 was used throughout this investigation. The organism was isolated in 1957 from a sputum sample of a human case of pulmonary nocardiosis at the Hopemont Sanitarium, Hopemont, West Virginia, U.S.A. Stock cultures were maintained on Sabouraud's dextrose agar slants at $4{ }^{\circ} \mathrm{C}$ with periodic passage on sheep-blood agar plates. Starter cultures were prepared by inoculating liquid media with several colonies from an agar slant. A I \% (v/v) inoculum from an actively growing culture was then used to seed the growth medium.

Defined medium. The synthetic growth medium used in all experiments was prepared by adding the following ingredients to approximately $800 \mathrm{ml}$ distilled water: $\mathrm{N}_{2} \mathrm{HPO}_{4}, 2 \cdot 2 \mathrm{~g}$; $\mathrm{KH}_{2} \mathrm{PO}_{4}, \mathrm{I} \cdot 32 \mathrm{~g} ; \mathrm{MgSO}_{4} .7 \mathrm{H}_{2} \mathrm{O}, 0.2 \mathrm{~g} ; \mathrm{Fe}_{2}\left(\mathrm{SO}_{4}\right)_{3}, 0.5 \mathrm{mg} ; \mathrm{MnSO}_{4} .4 \mathrm{H}_{2} \mathrm{O}, 0.2 \mathrm{mg} ; \mathrm{CaCl}_{2}$, $2.0 \mathrm{mg}$; glycine, $0.45 \mathrm{~g}$; malic acid, $3.3 \mathrm{~g}$; glucose, $10 \mathrm{~g}$; and ammonium hydroxide, $0.2 \mathrm{I} \mathrm{g}$. The $\mathrm{pH}$ was adjusted to 6.8 with $\mathrm{IO} \mathrm{N}-\mathrm{VaOH}$ and the volume made to $950 \mathrm{ml}$ with distilled water. A $20 \%(\mathrm{w} / \mathrm{v})$ aqueous solution of glucose was autoclaved separately and $50 \mathrm{ml}$ added aseptically to the sterilized medium. The organism was grown at $37^{\circ} \mathrm{C}$ in 21 Erlenmeyer flasks containing I 1 medium on a New Brunswick Model G-Io rotary shaker (New Brunswick Scientific Co., Inc., New Brunswick, New Jersey, U.S.A.), at I 80 rev./min, to ensure adequate aeration. To measure growth $10 \mathrm{ml}$ portions were dispersed with a glass tissue homogenizer (Bellco Glass, Vireland, New Jersey, U.S.A.) and read in a KlettSummerson colorimeter at $420 \mathrm{~nm}$ (filter 42). Cell suspensions were diluted, if necessary, to maintain readings in the linear range, i.e. less than 175 . A Klett reading of 100 was equivalent to approximately $0.5 \mathrm{mg} / \mathrm{ml}$.

Harvesting cultures and carbohydrate extraction. Bacteria were harvested by centrifuging in a Sorvall RC-2B refrigerated centrifuge at $13000 \mathrm{~g}$ for $30 \mathrm{~min}$, followed by washing with $4{ }^{\circ} \mathrm{C}$ distilled water. Alkali-soluble carbohydrate was extracted from approximately $8 \mathrm{~g}$ (wet wt) of bacteria by heating at $100{ }^{\circ} \mathrm{C}$ in $30 \%(\mathrm{w} / \mathrm{v}) \mathrm{KOH}$ for $45 \mathrm{~min}$. Debris removed by centrifuging at $5000 \mathrm{~g}$ for $\mathrm{I} 0 \mathrm{~min}$ was discarded and storage polysaccharide was precipitated from the supernatant by adding $\mathrm{r} \cdot 2$ vol. of $95 \%(\mathrm{v} / \mathrm{v})$ ethanol. Storage polysaccharide was collected by centrifuging at $15000 \mathrm{~g}$ for I $5 \mathrm{~min}$ and further purified by treatment with $95 \%(\mathrm{v} / \mathrm{v})$ ethanol and $10 \%(\mathrm{w} / \mathrm{v})$ trichloracetic acid (Cowgill \& Pardee, 1958). Carbohydrate was estimated by the anthrone method (Seifter, Dayton, Novic \& Muntwyler, I950), using D-glucose as a standard.

Acid hydrolysis. A purified sample of Nocardia glycogen ( $10 \mathrm{mg}$ ) was hydrolysed for $2 \mathrm{~h}$ in $\mathrm{I} \cdot \mathrm{O} \mathrm{M}-\mathrm{HCl}$ at $100{ }^{\circ} \mathrm{C}$ in a sealed tube. The hydrolysate was neutralized, evaporated in a rotary flash evaporator and re-dissolvec in distilled water. A $10 \mu 1$ portion (approximately $10 \mu \mathrm{g}$ of sugar) was applied to silica gel-impregnated glass-fibre paper, ITLC-SA (Gelman Instrument Co., Ann Arbor, Michigan, U.S.A.) which had been pretreated with O.I M$\mathrm{KH}_{2} \mathrm{PO}_{4}$ and activated for $\mathrm{I} h$ at $105{ }^{\circ} \mathrm{C}$. The components were separated by ascending one-dimensional chromatography in a closed chamber with a solvent consisting of chloroform:acetic acid: water $(55: 30: 5)$. The chromatogram was developed three successive times to distances of 10,13 and $15 \mathrm{~cm}$, respectively, before spraying with a solution of paraanisidine to locate sugars (Block, Durrun \& Zweig, 1958). Ten $\mu 1$ of a mixture of five sugars, Io $\mu \mathrm{g}$ each, was chromatographed simultaneously with the hydrolysate. The sugars and their respective $R_{F}$ values were: galactose, 0.22 ; glucose, 0.26 ; mannose, 0.3 I ; fructose, 0.38 ; ribose, 0.67 .

Iodine absorption. The absorption spectrum of the polysaccharide-iodine complex was measured in a Gilford 240 recording spectrophotometer after addition of Nocardia storage 
polysaccharide to a solution of $\mathrm{I}_{2}-\mathrm{KI}$ (Krisman, 1962). The spectrum produced was compared with that of soluble starch (Fisher Scientific, Pittsburgh, Pennsylvania, U.S.A.), rabbit-liver glycogen type III, and oyster glycogen type III (Sigma).

Enzyme hydrolysis. Glucose released from glycogen in the form of glucose I-phosphate by treatment with phosphorylase $a$ (Sigma) was measured spectrophotometrically by following the reduction of NAD in the presence of commercial phosphohexose isomerase and glucose 6-phosphate dehydrogenase (Boehringer Mannheim Corporation, New York, N.Y., U.S.A.) (Passonneau, Gatfield, Schulz \& Lowry, 1967). Commercial rabbit-liver glycogen type III served as a control.

End-group determination. The average chain length of Nocardia storage polysaccharide was determined on a $10 \mathrm{mg}$ sample by oxidation with sodium metaperiodate with methyl $\alpha$-D-glucoside as a standard (Fales, I959).

Electron microscopy. Bacteria collected from mid-exponential-phase cultures ( 2 days) by centrifuging for $30 \mathrm{~min}$ at $13700 \mathrm{~g}$ at $4{ }^{\circ} \mathrm{C}$ and then washed with distilled water were prefixed in $\mathrm{I} \%(\mathrm{v} / \mathrm{v})$ glutaraldehyde for $30 \mathrm{~min}$, fixed overnight in $\mathrm{I} \%(\mathrm{w} / \mathrm{v}) \mathrm{OsO}_{4}$ and embedded in Epon-8I 2 (Kellenberger, Ryter \& Séchaud, I958). Thin sections were cut on a Model MT-2 Porter-Blum ultramicrotome (Ivan Sorvall, Inc., Norwalk, Connecticut, U.S.A.) with a Dupont diamond knife, placed on copper grids previously covered with Formvar and carbon films, poststained with $2 \%(\mathrm{w} / \mathrm{v})$ aqueous uranyl acetate and $2 \%(\mathrm{w} / \mathrm{v})$ lead citrate (Reynolds, 1963) for 5 min each, and observed under an RCA electron microscope, Model EMU-3G, at $100 \mathrm{kV}$.

Thin sections were cytochemically stained for storage polysaccharide by using the glycogenspecific procedure of J. Revel and M. Karnovsky (personal communication). Sections prepared as previously described were mounted on Formvar and carbon-coated nickel grids and treated with solutions of $3 \%(\mathrm{w} / \mathrm{v}) \mathrm{H}_{2} \mathrm{O}_{2}, \mathrm{I} \%(\mathrm{w} / \mathrm{v})$ periodic acid and finally $2.5 \%(\mathrm{w} / \mathrm{v})$ sodium chlorite in $10 \mathrm{M}$-acetic acid, with rinsing in distilled water between treatments. Following the final rinse, grids were stained with $2 \%(\mathrm{w} / \mathrm{v})$ uranyl acetate $(5 \mathrm{~min})$ and $2 \%$ $(\mathrm{w} / \mathrm{v})$ lead citrate $(2 \mathrm{~min})$.

Negative staining. Glycogen isolated and purified from $N$. asteroides by cold water extraction (Bueding \& Orrell, 1964) was negatively stained according to the methods of Gordon (1972). A dilute aqueous solution containing $0.5 \mathrm{mg} / \mathrm{ml}$ was applied to a Formvar and carbon-support film and treated with an $0.3 \%(\mathrm{w} / \mathrm{v})$ solution of potassium phosphotungstate ( $\mathrm{pH} 7 \cdot 0$ ). Commercial cold water-extracted rabbit-liver glycogen, type V (Sigma), was also negatively stained.

\section{RESULTS}

\section{Structural analysis}

Development of thin-layer chromatographs of the acid-hydrolysed storage polysaccharide revealed a single compound with $R_{F} \mathrm{O} \cdot 27$, indicating that glucose was the only monomeric sugar unit present. Treatment of the polysaccharide with commercial phosphorylase $a$ rapidly released glucose I-phosphate, indicating the presence of $\alpha$-I, 4 -linked glucose residues in the structure (Fig. I). The rate of degradation equalled that obtained using commercial rabbit-liver glycogen. According to Passonneau et al. (1967) the small increase in extinction observed during the secondary phase of glycogen degradation is due to the presence of $\alpha-I, 6$ branched linkages in the structure.

The wavelength of maximum absorption of the polysaccharide-iodine complex was 450 to $460 \mathrm{~nm}$. When compared with several well-characterized commercial preparations of glycogens (Fig. 2) the spectrum was most similar to that produced by rabbit-liver glycogen. 


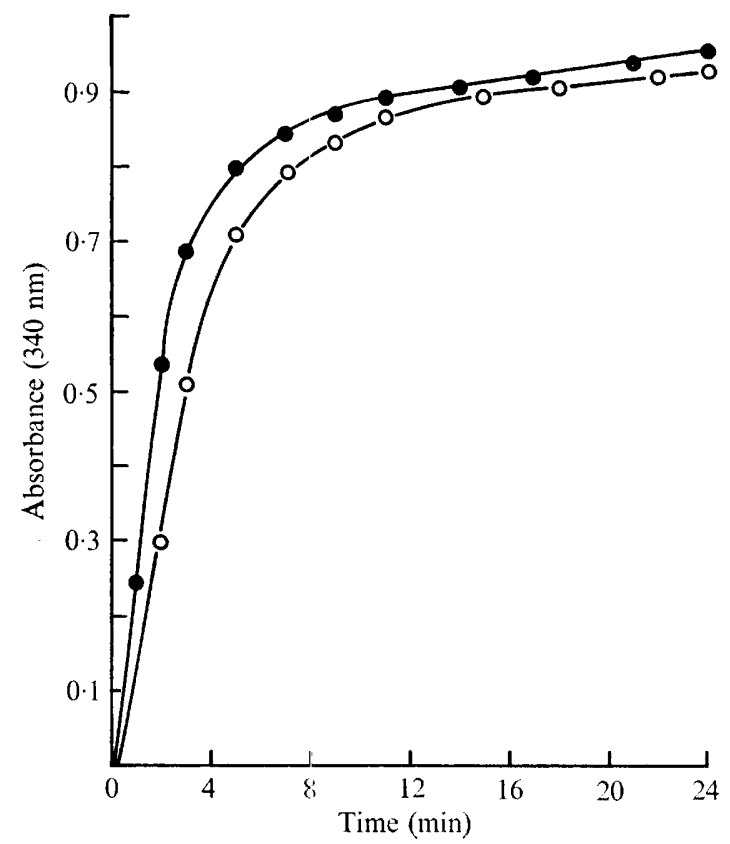

Fig. I. The effect of phosphorylase $a$ on $(\bullet)$ commercial rabbit-liver glycogen $(0.3 \mathrm{~mm})$ and $(\bigcirc)$ Nocardic asteroides storage polysaccharide.

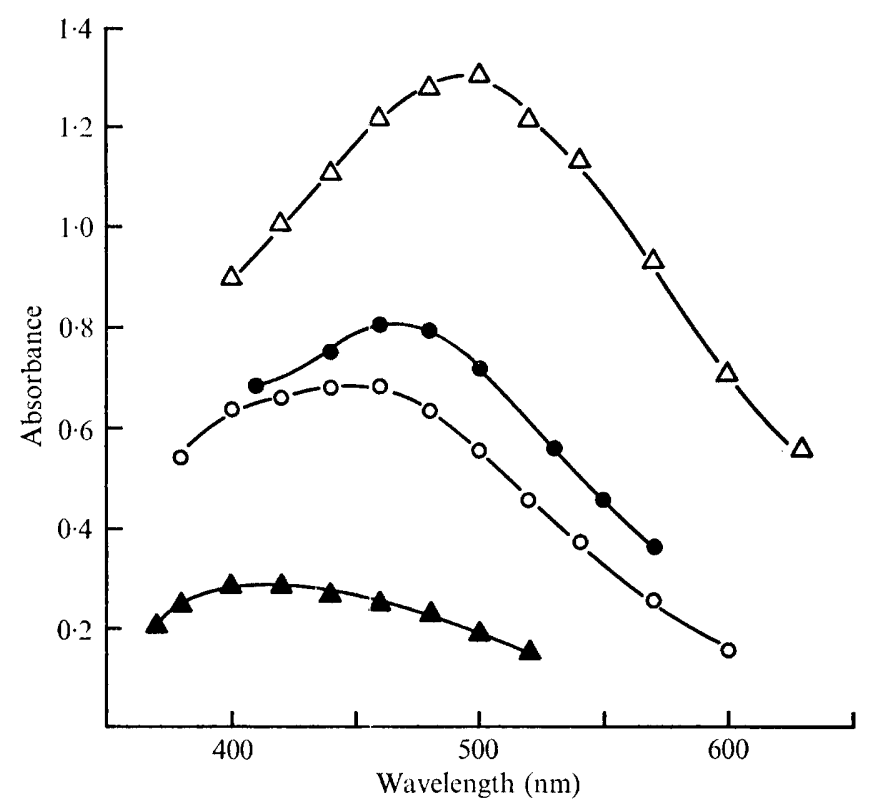

Fig. 2. The iodine absorption spectra of rabbit-liver glycogen $(\boldsymbol{\bullet})$, oyster glycogen $(\mathbf{\Lambda})$, Nocardia asteroides storage polysaccharide $(O)$, and soluble starch $(\triangle)$. 
Table I. Structural properties of glycogens isolated from various sources

$\begin{array}{lcc}\text { Glycogen sources } & \begin{array}{c}\text { Average chain } \\ \text { length* }\end{array} & \begin{array}{c}\text { Maximum } \\ \text { absorption }(\mathrm{nm})\end{array} \\ \text { Nocardia asteroides } & 1 \mathrm{I} \cdot 6 \dagger & 450-460 \\ \text { Rabbit liver } & 17 \cdot 0 & 460 \\ \text { Oyster } & 12 \cdot 0 & 410 \\ \text { Escherichia colit\$ } & 10 \cdot 0-13 \cdot 0 & 420-455 \\ \text { Aerobacter aerogenes } & 13 \cdot 0 & 485 \\ \text { Arthrobacter sp. } & 9 \cdot 0 & 420-440 \\ \text { ured as glucosyl units. } & & \\ \text { ge value of two separate tests each containing triplicate determinations. } \\ \text { Co five strains tested. }\end{array}$

Glycogen isolated from bacteria during peak accumulation (5 days) had an average chain length of $\mathrm{I}$ I 6 glucosyl units as determined by end-group analysis. This value was compared with commercial rabbit-liver and oyster glycogens and with values obtained by other investigators by using the same periodate oxidation procedure of Fales (I959) to analyse glycogens from other bacteria (Table I).

\section{Electron microscopy}

Thin sections of $N$. asteroides harvested in mid-exponential phase of growth ( 2 days) showed large cytoplasmic vacuoles (Fig. 3), believed to be composed of lipid material. In addition, many bacteria also contained smaller vacuoles, 60 to $100 \mathrm{~nm}$ in diameter (Fig. 4), which were similar in size and shape to the glycogen storage granules observed in thin sections of Streptococcus mitis (Berman et al. 1967) and Arthrobacter crystallopoietes (Boylen $\&$ Pate, 1973). To distinguish glycogen granules from lipid-containing vacuoles more readily, thin sections were also treated with a glycogen-specific stain (Figs. 5 and 6). The bacteria now revealed numerous darkly stained bodies, 60 to $100 \mathrm{~nm}$ in diameter, distributed throughout the cytoplasm. Lipid vacuoles remained unstained and were clearly distinguishable from glycogen granules. When the periodate oxidation step was omitted from the glycogenstaining procedure, glycogen granules did not stain and only lipid vacuoles were visible in the sections (Fig. 7).

Negatively stained preparations of commercial rabbit-liver glycogen extracted with cold water (Fig. 8) revealed $\alpha$-particles as large as $200 \mathrm{~nm}$ in diameter, composed of numerous subunits ( $\beta$-particles). Similarly stained preparations of nocardial glycogen, extracted also with cold water (Fig. 9), revealed $\alpha$-particles 60 to $100 \mathrm{~nm}$ in diameter which lacked a definite subunit structure. The comparable size of isolated $\alpha$-particles and intracellular glycogen granules indicated that the $\alpha$-particles were little degraded during the cold water extraction.

\section{DISCUSSION}

In bacteria the common reserve compounds, which include lipid, poly- $\beta$-hydroxybutyrate, glycogen and polyphosphate, are stored in various types of cytoplasmic vacuoles, granules or solid inclusions. These storage units, which generally are not membrane-limited, can often be detected cytochemically or in thin sections viewed under the electron microscope. According to Kellenberger \& Ryter (I964), glycogen particles usually appear as small, round granules of rather diffuse outline. Their empty appearance reflects the low electronscattering power common to all polysaccharides. This observation adequately describes the 

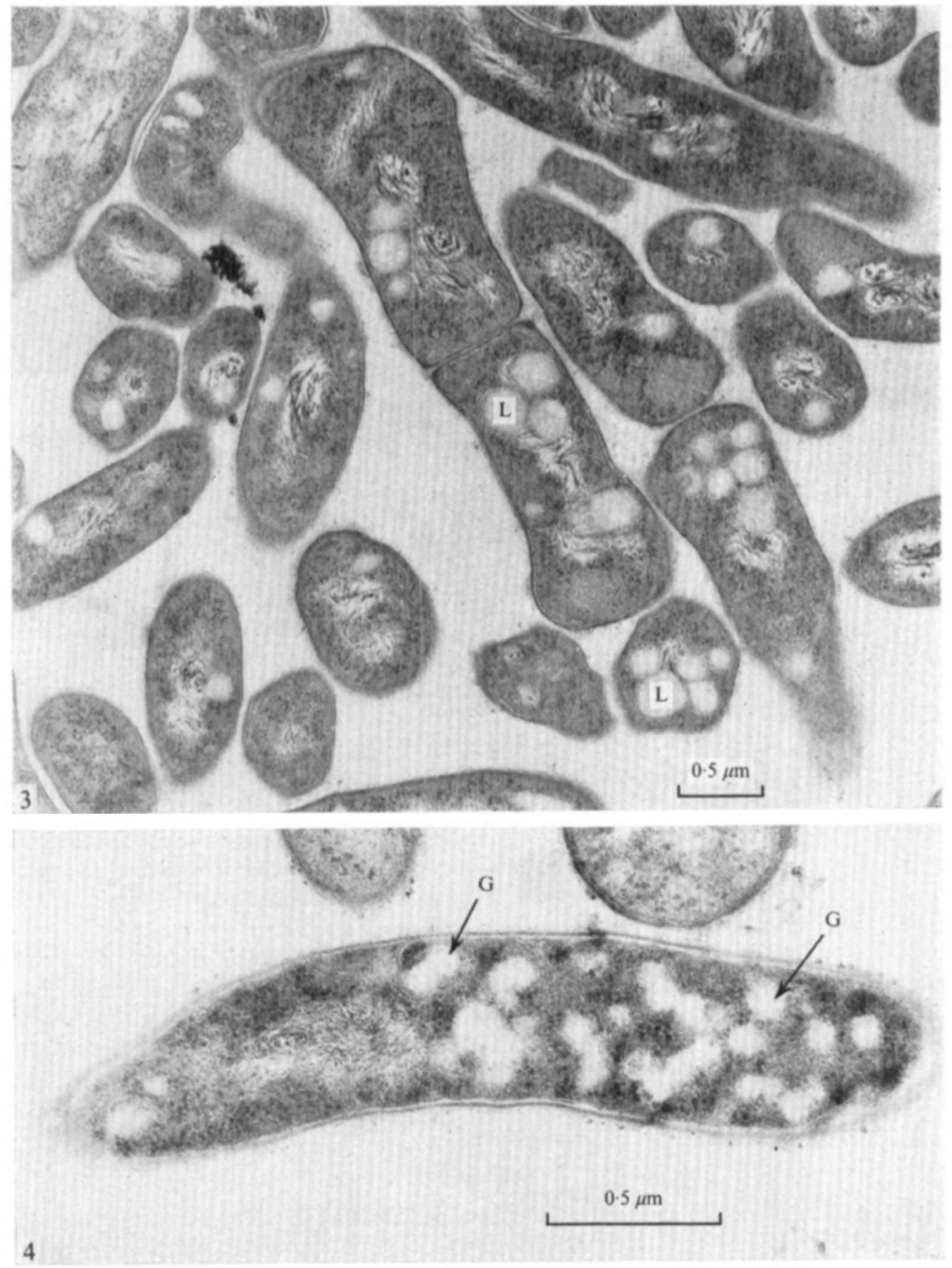

Fig. 3. Thin section of 2-day-old $N$. asteroides poststained with uranyl acetate and lead citrate. L, lipid-containing vacuoles.

Fig. 4. Thin section of 2-day-old N. asteroides poststained with uranyl acetate and lead citrate. $\mathrm{G}$, glycogen granules. 

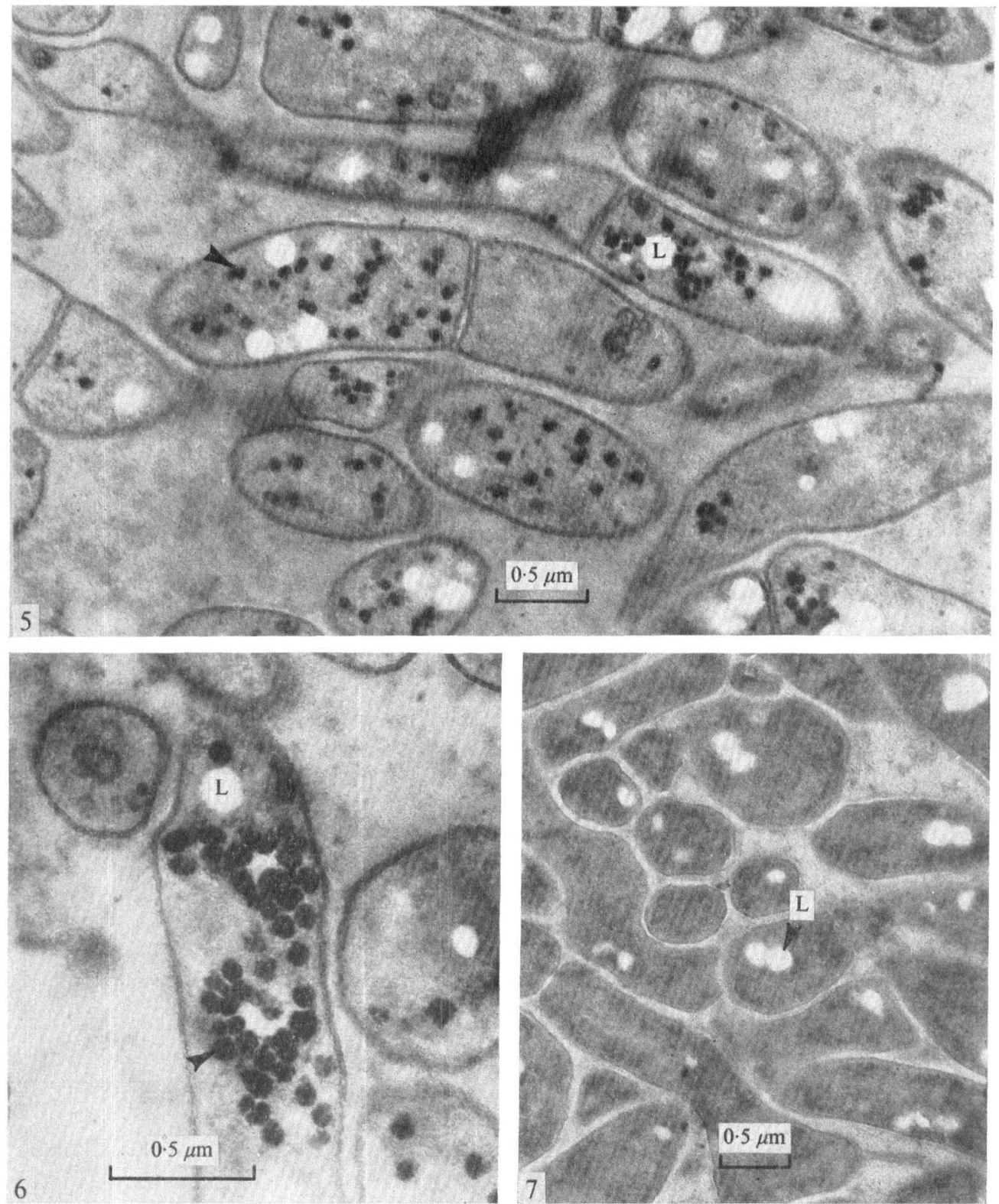

Figs. 5 and 6. Thin sections of 2-day-old Nocardia asteroides treated with a glycogen-specific stain. $\mathrm{L}$, lipid-containing vacuoles; arrow, glycogen granules.

Fig. 7. Thin section of 2-day-old Nocardia asteroides treated with a glycogen-specific stain with the periodic acid-oxidation step omitted. L, lipid-containing vacuoles.

appearance of cytoplasmic granules produced by cells of $N$. asteroides grown in a nitrogenlimiting, glucose-supplemented medium.

Nocardia asteroides when grown under nitrogen-limiting conditions (McFarland, 1967) accumulates up to $40 \%$ of its dry weight as neutral lipids, which include fatty acids, glycerides and waxes. Poly- $\beta$-hydroxybutyrate, however, is not produced. In the present investigation 

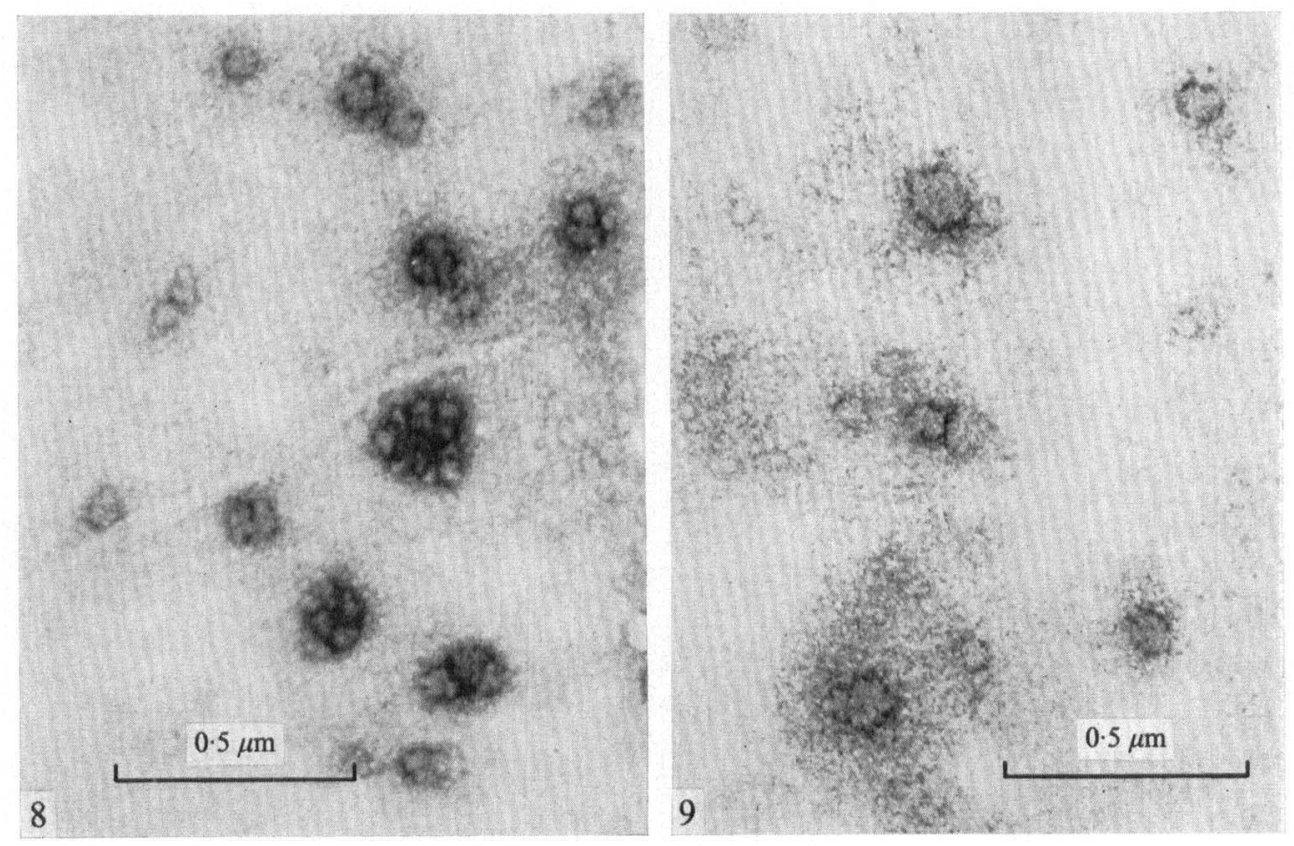

Fig. 8. Negatively stained commercial cold water-extracted rabbit-liver glycogen granules.

Fig. 9. Negatively stained, cold water-extracted Nocardia glycogen granules.

large vacuoles were observed in thin sections, in addition to glycogen granules, and probably function as depots for neutral lipid storage.

Glycogen granules could not be seen in early stationary-phase cells (5 days) without the use of the glycogen stain, even though glycogen accumulation is known to reach a maximum during this portion of the growth cycle. Although lipid vacuoles were still observable, the extreme disorganization of cytoplasmic constituents made differentiation of the smaller glycogen granules difficult in unstained sections (Fig. 10). Similar results were obtained by Boylen \& Pate (1973), who found that glycogen storage granules could not be seen in thin sections of starved Arthrobacter crystallopoietes, even though the bacteria contained as much as $50 \%$ of their original anthrone-positive carbohydrate. With the use of the glycogen stain it became evident that $N$. asteroides continued to produce glycogen granules well into the stationary phase of growth (Fig. II).

Although nocardial glycogen shows a chemical similarity to glycogens isolated from other organisms, the structure of Nocardia $\alpha$-particles, extracted with cold water, shows a marked difference from the structure of rabbit-liver glycogen. The indistinct nature of the nocardial $\alpha$-particles was similar to the appearance of glycogens isolated with cold water from species of Mycobacterium (Antoine \& Tepper, 1969) which also lack a clearly defined subunittype structure. 


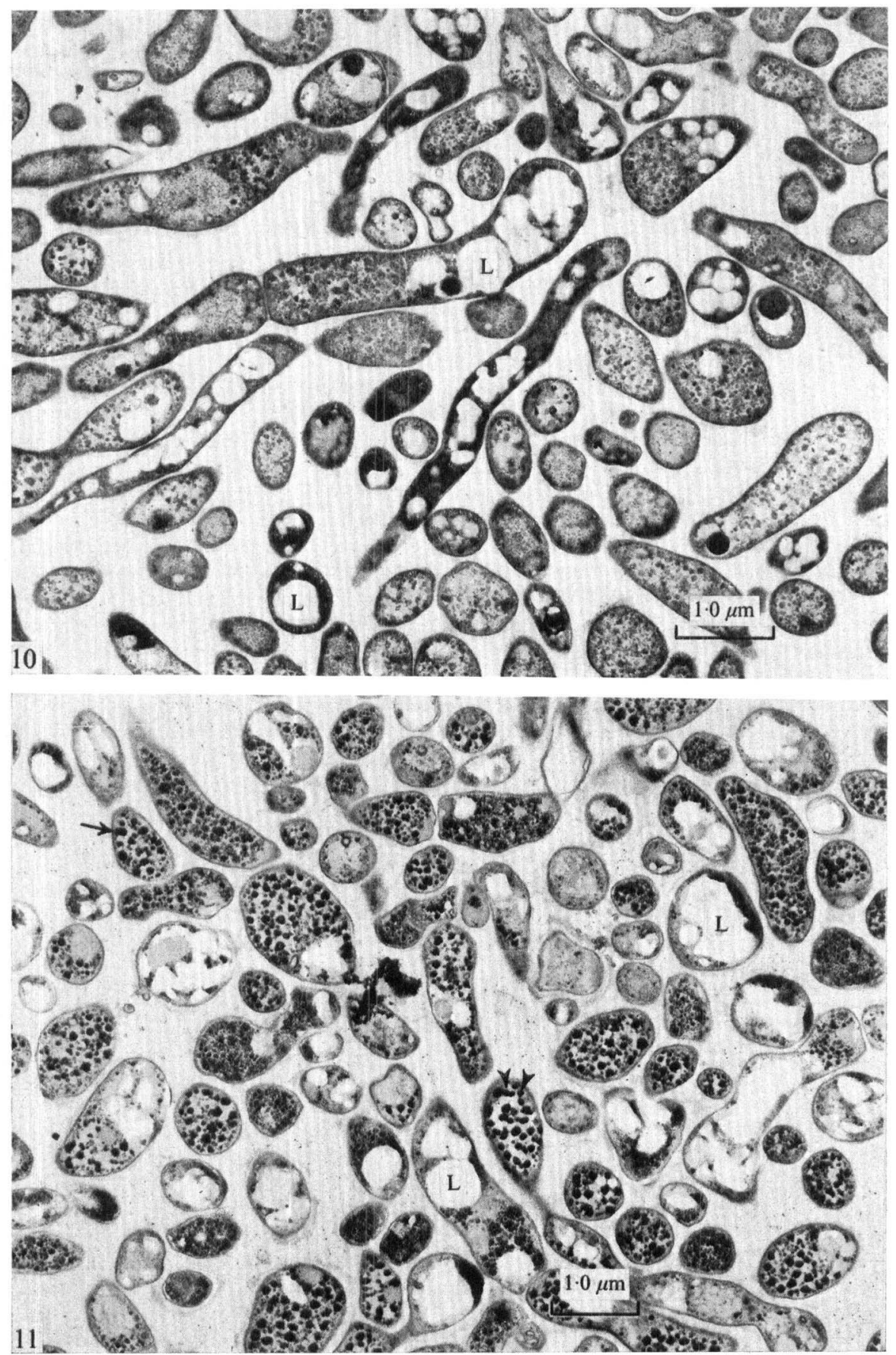

Fig. 10. Thin section of 5-day-old $N$. asteroides poststained with uranyl acetate and lead citrate. L, lipid-containing vacuoles.

Fig. II. Thin sections of 5-day-old $N$. asteroides treated with a glycogen-specific stain. L, lipidcontaining vacuoles; arrow, glycogen granules. 


\section{REFERENCES}

Antoine, A. D. \& TePper, B. S. (1969). Characterization of glycogens from mycobacteria. Archives of Biochemistry and Biophysics r34, 207-213.

Berman, K.S., Gibbons, R. J. \& Nalbandian, J. (I967). Localization of intracellular polysaccharide granules in Streptococcus mitis. Archives of Oral Biology 12, I $133-1$ I 38.

Block, R. J., Durrum, E. L. \& Zweig, G. (1958). Manual of Paper Chromatography and Paper Electrophoresis, and edn, p. 182. New York: Academic Press.

Boylen, C. W. \& PATE, J. L. (1973). Fine structure of Arthrobacter crystallopoietes during long-term starvation of rod and spherical stage cells. Canadian Journal of Microbiology I9, I-5.

Bueding, E. \& OrRell, S. A. (1964). A mild procedure for the isolation of polydisperse glycogen from animal tissues. Journal of Biological Chemistry 239, 4018-4020.

Cedergren, B. \& Holme, T. (r959). On the glycogen of E. coli B. Electron microscopy of ultrathin sections of cells. Journal of Ultrastructural Research 3, 70-73.

Cowgill, R. W. \& PardeE, A. B. (1958). Experiments in Biochemical Research Techniques, p. I 57. New York: John Wiley.

FALES, F. W. (1959). A reproducible periodate oxidation method for the determination of glycogen endgroups. Analytical Chemistry 31, I $898-1900$.

Ghosh, H. P. \& Preiss, J. (1965). The isolation and characterization of glycogen from Arthrobacter sp. NRRL B 1973. Biochimica et biophysica acta 104, 274-277.

Gordon, C. N. (1972). The use of octadecanol monolayers as wetting agents in the negative staining technique. Journal of Ultrastructural Research 39, I73-185.

Holme, T. \& Cedergren, B. (196I). Demonstration of intracellular polysaccharide in $E$. coli by electron microscopy and by cytochemical methods. Acta pathologica et microbiologica scandinavica 51, $170-186$.

Kellenberger, E. \& Ryter, A. (1964). In bacteriology. In Modern Developments in Electron Microscopy, p. 335. Edited by B. M. Siegel. New York: Academic Press.

Kellenberger, E., Ryter, A. \& Séchaud, J. ( 1958). Electron microscopic study of DNA-containing plasms. II. Vegetative and mature phage DNA as compared with normal bacterial nucleoids in different physiological states. Journal of Biophysical and Biochemical Cytology 4, 67 I-678.

Krisman, C. R. (I962). A method for the colorimetric estimation of glycogen with iodine. Analytical Biochemistry 4, $17-23$.

MCFARLAND, C. R. (1967). Neutral lipids as endogenous carbon and energy reserves in Nocardia asteroides. Ph.D. dissertation, West Virginia University, Morgantown, West Virginia, U.S.A.

Passonneau, J. V., Gatfield, P. D., Schulz, D. W. \& Lowry, O. H. (1967). An enzymic method for measurement of glycogen. Analytical Biochemistry 19, 31 5-326.

REYNOLDS, E. S. ( 1963 ). The use of lead citrate at high $\mathrm{pH}$ as an electron opaque stain in electron microscopy. Journal of Cellular Biology $\mathbf{1 7}, 208-212$.

Sinfter, S., Dayton, S., Novic, B. \& Muntwyler, E. (1950). The estimation of glycogen with the anthrone reagent. Archives of Biochemistry 25, 19I-200.

Sigal, N., Cattaneo, J. \& Segel, I. H. (1964). Glycogen accumulation by wild-type and uridine diphosphate glucose pyrophosphorylase-negative strains of Escherichia coli. Archives of Biochemistry and Biophysics I08, 440-45I.

Watson, S. W., Graham, L. B., Remsen, C. C. \& Valois, F. W. (1971). A lobar, ammonia-oxidizing bacterium, Nitrosolobus multiformis nov. gen. nov. sp. Archiv fïr Mikrobiologie 76, 183-203.

Watson, S. W. \& Waterbury, J. B. (1971). Characteristics of two marine nitrate oxidizing bacteria, Nitrospina gracilis nov. gen. nov. sp. and Nitrococcus mobilis nov. gen. nov. sp. Archiv fïr Mikrobiologie 77, $203-230$.

Voelz, H., Voelz, U. \& Ortigoza, R. O. (1966). The 'polyphosphate overplus' phenomenon in Myxococcus xanthus and its influence on the architecture of the cell. Archiv fiir Mikrobiologie 53, 37 I-388. 